\title{
Türkiye Ekonomisi Cari Açığı Sürdürülebilir Mi? Birim Kök Testleriyle Bir İnceleme*
}

\author{
Harun SARAÇ ${ }^{1}$ \\ Uğur SIVRİ $\dot{I}^{2}$
}

ÖZ: Bu çalışmada, Türkiye ekonomisi cari açı̆̆ının sürdürülebilirliği 1992:I-2017:IV dönemine ait çeyreklik cari denge Gayrisafi Yurtiçi Hasıla (GDP) oranı ve 1992:01-2017:12 dönemine ait aylık reel cari denge ve kişi başına reel cari denge olmak üzere ü̧̈ ayrl seriye uygulanan kırılmall ve kırılmasız birim-kök testleri ile analiz edilmektedir. Kırılması birimkök test sonuçları genel olarak serilerin durağan olmadı̆̆ını, tersine kırılmalı birim-kök test sonuçları ise genel olarak serilerin durağan ve dolayısıyla cari açığın sürdürülebilir olduğunu göstermektedir. Her ne kadar Türkiye ekonomisi cari açı̆̆ kırılmaların dikkate alınması durumunda durağan bulunsa da, durağan bulunan "(Cari Açı)/GDP" serisinin ortalaması çok yüksek ve literatürde kriz eşiği olarak görülen oranlara oldukça yakındır. Bu nedenle cari açı önemli bir sorun olarak ele alınmalı ve göz ardı edilmemelidir.

Anahtar Kelimeler: Cari Açı, Sürdürülebilirlik, Türkiye Ekonomisi, Birim Kök Testleri. JEL Kodlart: F32, F41, C22.

\section{Is Current Account Deficit of the Turkish Economy Sustainable? An Investigation with Unit Root Tests}

\begin{abstract}
In this study, the sustainability of the current account deficit of Turkish economy is analysed for three different time series, namely quarterly current account balance to Gross Domestic Product (GDP) ratio covering 1992:I-2017:IV period, monthly real current account balance and monthly real per capita current account balance, both of which cover the 1992:012017:12 period, by using unit-root tests with and without break. Results of unit root tests without break generally show that series are nonstationary while, on the contrary, results of unit root tests with break generally show that series are stationary and therefore current account deficit is sustainable. Although current account deficit of the Turkish economy is found to be stationary with breaks, an average value of the stationary "(Current Account $D e f i c i t) / G D P$ "series is very high and close to the ratios that are regarded as a crisis level in the literature. Therefore current account deficit should be seen as an important problem and should not be disregarded.
\end{abstract}

Key Words: Current Account Deficit, Sustainability, Turkish Economy, Unit Root Tests JEL Codes: F32, F41, C22.

\footnotetext{
*Bu çalışma Harun SARAÇ’ın “Cari Açıkların Sürdürülebilirliği: Uygulamalı Türkiye Analizi” adlı yüksek lisans tezinden üretilmiştir.

1 Araştırma Görevlisi, Recep Tayyip Erdoğan Üniversitesi, İktisadi ve İdari Bilimler Fakültesi, İktisat Bölümü, harun.sarac@erdogan.edu.tr, orcid.org/0000-0002-4576-9273.

${ }^{2}$ Doç. Dr., Recep Tayyip Erdoğan Üniversitesi, İktisadi ve İdari Bilimler Fakültesi, İktisat Bölümü, ugur.sivri@erdogan.edu.tr, orcid.org/0000-0002-1459-4415.
} 


\section{Giriş}

Ekonomilerin dış borç stokunu arttırma potansiyeline sahip bir kalem olan cari açıkların sürdürülebilirlik kriterleri bağlamında üç önemli soru ile karşılaşılmaktadır: i. Borçlu ülke ödeme gücüne sahip (solvent) midir? ii. Mevcut dış dengesizlik sürdürülebilir (sustainable) midir? iii. Mevcut cari açık aşırı (excessive) mıdır? $\mathrm{Bu}$ üç soru birbiriyle bağlantılı olması yanında sürdürülebilirliğin analiz edildiği çalışmalarda s1kça sorulan ve başvurulan kavramları içermektedir (Milesi-Ferretti ve Razin, 1996: 2). Bir ülkenin cari açığı aşırı (excessive) ise ülke ekonomisi bir süre sonra borçlarını ödeyebilme (solvent) yeteneğini kaybedecektir. Borçlarını temerrüde düşüren bir ülkede cari açığın sürdürülebilir (sustainable) olduğundan bahsedilemez.

Bir ülke, kısa vadede yüksek seviyelerdeki tüketiminden kaynaklanan cari açığını dış ülkelerden borç alarak sürdürebilir. Fakat cari açık devamlılık gösterirse bir noktadan sonra ülkenin borç ödeme gücü ve yeteneği sorgulanmaya başlar. Dolayısıyla borç veren ülkeler, borçlu ülkenin borçlarını vadesinde geri ödeyemeyecek noktaya gelmeden cari açığını sürdürüp sürdüremeyeceğini bilmek isteyeceklerdir. Diğer taraftan borçlu ülke borç alma imkânlarını kaybettiği takdirde kronik cari açıklarına çözüm arayışına girmek durumunda kalacaktır (Wickens ve Uctum, 1993: 424). Tüm bu faktörler hem borçlu hem de borç veren ülkeler için cari açığın sürdürülebilirliğinin doğru analiz edilmesini ve bu tespit için kullanılacak yöntemleri önemli hale getirmektedir.

Yerli ve yabancı literatürde cari açıkların sürdürülebilirliğine dair gerçekleştirilen uygulamalı çalışmalarda kullanılan yöntemler genel olarak ikiye ayrılmaktadır: dönemler-arası bütçe kısıtı ve dönemler-arası tüketim dalgalanmalarının giderilmesi modelleri. Birinci tip model Hakkio ve Rush (1991)'in geliştirdiği, Husted (1992)'nin ekonometrik olarak test edilebilir bir seviyeye getirdiği ve açıkların sürdürülebilirliğini ithalat ve ihracat serilerinin eş-bütünleşik olması ile açıklamaya çalışan modeldir.

İkinci tip çalışmalarda ise gerçekleşen cari açık ve kurulan tüketim dalgalanmaları modelinden elde edilen optimal cari açık mukayese edilerek cari açığın sürdürülebilir olup olmadiğı test edilmektedir. Ghosh (1995), Ghosh ve Ostry (1995)'in öncülük ettiği, Cashin ve McDermott (1998)'in sürdürdügü bu tür çalışmalarda cari açıklar, gerçekleşen yatırım ve kamu harcamalarındaki şoklar karşısında özel kesimin tüketimindeki dalgalanmalara mani olan bir tampon olarak değerlendirilmektedir. Bu yaklaşım cari dengenin tipik olarak durağan serilerden oluştuğunu ima eder. Uygulamalı analizlerin önemli bir kısmı da Campbell ve Shiller (1987)'nin geliştirdiği tekniği kullanarak cari dengenin dönemler-arası yaklaşımı sağlayıp sağlamadığını test etmektedir. Bununla beraber ilgili çalışmaların genel özelliği Dickey ve Fuller (1979, bundan sonra DF) gibi geleneksel birim-kök testlerini uygulayarak durağanlık analizleri yapmak şeklindedir (Wu, 2000). Trehan ve Walsh (1991)'e göre de cari dengenin durağan olması dönemler-arası bütçe kısıtının sağlanması için yeterli bir koşul olmaktadır. 
Cari işlemler hesabının özelliklerine yönelik çalışmalara göre eğer cari işlemler hesabında durağanlık (stationarity) gözlenmiyorsa, cari işlemler hesabı ortalamaya dönüş (mean-reverting) sergilememektedir ve sürdürülebilirliği tehlikededir. Bu seyir ilerleyen dönemlerde de tekrar edecek olursa ülke ekonomisi büyük bir krize girecek, borçlarını ödeyemediği için tüm kredisini kaybedecek ve uluslararası piyasa ile bağlarını koparma durumuna gelecektir (Chen, 2011: 1455).

Kullanılan yöntem ve uygulanan testlerdeki farklılıklar uygulamalı çalışmalarda tartışmalı sonuçlara da yol açabilmektedir. Örneğin Amerika Birleşik Devletleri cari açıklarının sürdürülebilirliğine dair yapılan çalışmalardan $\mathrm{Wu}$, Chen ve Lee (2001)'e göre geleneksel birim-kök ve eş-bütünleşme testleri uygulandığında sürdürülemez olduğu sonucuna varılan $\mathrm{ABD}$ cari açığı, panel eş-bütünleşme yöntemi kullanıldığında sürdürülebilir olarak elde edilmiştir. Benzer şekilde 19701990 dönemi ABD için sürdürülebilirlik analizi yapan Liu ve Tanner (1996), kırılmasız geleneksel birim-kök testleri uyguladığında sürdürülebilir bulmadığı cari açığın, kırılmaları dahil ederek yaptığı analiz sonucunda sürdürülebilir olduğunu ifade etmiştir. Fountas ve Wu (1999), geleneksel birim-kök testlerine ek olarak eşbütünleşme testleri uygulamış ve serinin sürdürülebilir olmadığı sonucuna ulaşmışlardır. Bu sonuçların aksine Matsubayashi (2005), dönemler-arası bütçe kısıtı yaklaşımı üzerinden yaptığı zaman serisi çalışmasında ABD'nin sürdürülebilirlik kriterlerini ihlal etmediğine yönelik bulgulara ulaşmıştır.

Kullanılan yöntemlere göre sonuçlar çeşitlilik gösterse de literatürün önemli bir kısmında cari işlemler dengesinin ortalamaya dönüş sergilemesi yani borçların ödenebilir olup olmamasının tespit edilmesinde cari işlemler dengesine dair çeşitli durağanlık testlerinin uygulandığı görülmektedir. Nitekim Liu ve Tanner (1996) durağanlık testlerinin eş-bütünleşme testlerine nazaran avantajları olduğunu vurgulamıştır. Kurulan model bağlamında X (İhracat), M (İthalat) ve f(Uluslararası Varlık Pozisyonu) değişkenleri üzerine eş-bütünleşme testleri uygulanarak da ödeme koşulunun sağlanıp sağlanmadığı görülebilir. Fakat yöntem olarak durağanlık testlerinin kullanılmasının dört temel avantajı vardır (Liu ve Tanner, 1996: 741): i. Eş-bütünleşme testleri X, M ve f değişkenleri arasında $\left[\begin{array}{ll}1,-1, \quad r\end{array}\right]$ eş-bütünleşme vektör katsayılarını gerekli kılmaktadır (r: faiz oranı). ii. Trehan ve Walsh (1991)'in de ifade ettiği gibi eş-bütünleşme testleri için faiz oranlarının sabit olması gerekliliği vardır. Buna karşılık durağanlık testlerinde böyle bir kısıt bulunmamaktadır. iii. Durağanlık testlerinde sonuçların isabetli olabilmesi için X, $M$ ve f'nin tesadüfi yürüyüș (random walk) özelliği göstermesi gibi bir zorunluluk yoktur. iv. Herhangi bir ülkenin uluslararası varlık pozisyonuna yani $\mathrm{f}$ ile ifade edilen değişkene dair net bir veriye ulaşmak oldukça zordur. Bu sebeplerden ötürü cari işlemler dengesinin sürdürülebilirliğine dair analizlerde durağanlık testleri, eşbütünleşme testlerine göre daha uygundur ve daha isabetli sonuçlar vermektedir.

$\mathrm{Bu}$ çalışmada karakteristik olarak açık veren Türkiye ekonomisi cari işlemler dengesinin ortalamaya dönüş sergileyip sergilemediği ve dolayısıyla sürdürülebilir olup olmadığının tespit edilmesi amaçlanmaktadır. Bu amaçla cari işlemler 
dengesine dair oluşturulan üç farklı seri üzerinde yapısal kırılmalı ve kırılmasız birim kök testleri uygulanarak elde edilen sonuçlar değerlendirilecektir. Çalışmanın geri kalan bölümü şu şekilde düzenlenmiştir: İkinci bölümde çalışmada kullanılan veri seti ve ekonometrik yöntem tanıtılacaktır. Üçüncü bölümde bulgular sunulacak, dördüncü ve son bölümde ise genel bir değerlendirme yapılacaktır.

\section{Veri Seti ve Ekonometrik Yöntem}

Bu çalışmada Türkiye ekonomisi cari işlemler dengesi 1992:01-2017:12 dönemi için aylık ve üçer aylık frekansta analiz edilecektir. Analizin 1992:01 dönemi itibariyle başlamasının nedeni, aylık frekansta daha önceki dönemlere ait verilere ulaşılamamasıdır.

Bu çalışmada cari dengeyi temsil edecek biçimde oluşturulan ilk seri çeyreklik "(Cari İşlemler Dengesi)/GDP” serisidir. Cari işlemler hesabına dair veri Türkiye Cumhuriyet Merkez Bankası (TCMB) Elektronik Veri Dağıtım Sistemi (EVDS) aracılığıyla elde edilmiştir. $\mathrm{Bu}$ seri ABD doları cinsindendir. Diğer taraftan Gayrisafi Yurtiçi Hasıla (GDP) verileri üçer aylık frekanstadır. Dolayısıyla cari denge serisi ile GDP serisinin frekansını uyumlu hale getirmek için aylık frekanstaki cari denge serisi toplulaştırılarak üçer aylık hale getirilmiştir. TCMB'den elde edilen 1998 bazlı GDP verileri 1998 yılının birinci çeyreğinden başladığ1 için, GDP verilerinin 1992:I-1997:IV dönemine ait kısmı Uluslararası Para Fonu (International Monetary Fund) tarafindan yayınlanan Uluslararası Finansal İstatistikler (International Financial Statistics) yayınından derlenmiştir. TCMB'den alınan ve Türk Lirası cinsinden olan 1998:I-2017:IV dönemine ait GDP verisi, Federal Reserve Bank'ın veri tabanından elde edilen aynı döneme ait çeyreklik ortalama döviz kuru değerleri kullanılarak ABD dolarına çevrilmiştir. Böylece ABD doları cinsinden elde edilen iki seri birbirine oranlanarak (Cari İşlemler Dengesi)/GDP serisi 1992:I-2017:IV dönemi için elde edilmiştir.

Bu çalışmada cari dengeyi temsil edecek biçimde oluşturulan ikinci seri aylık "Reel Cari Denge" serisidir. Yukarıda ifade edildiği gibi ABD doları cinsinden oluşturulan Türkiye ekonomisi cari işlemler hesabı dengesi aylık olarak 1992:012017:12 dönemini kapsamaktadır. Söz konusu seri, dolar cinsinden fiyat artışlarını temsil eden Tüketici Fiyat Endeksi (CPI) kullanılarak enflasyondan arındırılmış ve reel hale getirilmiştir. İlgili döneme ait aylık CPI verileri Federal Reserve Bank (FED)'in resmi internet sitesindeki FRED (Federal Reserve Economic Data) veri tabanından alınmıştır. Böylece ABD doları cinsinden reel cari denge serisi 1992:012017:12 dönemi için elde edilmiştir.

$\mathrm{Bu}$ çalışmada cari dengeyi temsil edecek biçimde oluşturulan üçüncü seri "Kişi Başına Reel Cari Denge" serisidir. Bu seriyi oluşturmak için aylık frekansta nüfus serisine ihtiyaç duyulmaktadır. Bunun için 1990 ve 2000 yılı genel nüfus sayımı sonuçları Türkiye İstatistik Kurumu (TÜİK) yayınlarından TÜíK (2018a), 20072017 yıllarına ait yıllık Adrese Dayalı Nüfus Kayıt Sistemi (ADNKS) nüfus verileri ise TÜíK (2018b)'den derlenmiştir. Toplanan ve düzenli bir frekansı olmayan nüfus 
verileri Malthusçu (üstel) nüfus büyüme formülü kullanılarak aylık nüfus verilerine dönüştürülmüştür. Daha önce oluşturulan aylık reel cari denge serisi aylık nüfus serisine oranlanarak kişi başına reel cari denge serisi 1992:01-2017:12 dönemi için elde edilmiştir.

Bu çalışmada cari dengeyi temsil edecek biçimde oluşturulan üç ayrı serinin temel özellikleri aşağıdaki Tablo 1'de özetlenmektedir.

Tablo 1: Oluşturulan Cari Denge Serileri

\begin{tabular}{l|l}
\hline Seri Adı & Veri Özellikleri \\
\hline i. Cari İşlemler Dengesinin GDP'ye Oranı, & Çeyreklik, 1992:I-2017:IV dönemi, \\
[(Cari İslemler Dengesi)/GDP*100] & 104 gözlem \\
\hline ii. Reel Cari İşlemler Dengesi & Ayllk, 1992:01-2017:12 dönemi, \\
& 312 gözlem \\
\hline iii. Kişi Başına Reel Cari Denge & Ayl1k, 1992:01-2017:12 dönemi, \\
& 312 gözlem \\
\hline
\end{tabular}

Tablo 1'de görüldüğü üzere, üçer aylık cari işlemler dengesinin GDP'ye oranı serisi 1992:I-2017:IV dönemini kapsamaktadır ve 104 gözlemden oluşmaktadır. Aylık reel cari işlemler dengesi ve yine aylık kişi başına reel cari denge serileri ise 1992:01-2017:12 dönemini kapsamaktadır ve 312'şer gözlemden oluşmaktadır.

$\mathrm{Bu}$ çalışmada Türkiye ekonomisi cari açıklarının sürdürülebilirliğini incelemek amacıyla hem yapısal kırılmayı içermeyen hem de yapısal kırılmayı dikkate alan birim kök testleri kullanılacaktır. Bu amaçla kullanılacak testler aşağıda tanitılmaktadir.

\subsection{Genişletilmiş Dickey-Fuller (ADF) Testi}

ADF, DF testinin genişletilmiş hali olarak zaman serilerinin durağan olup olmadığının test edilmesinde yaygın olarak kullanılan birim kök testlerinden biridir. $\mathrm{Bu}$ çalışmada ADF denklemlerinin aşağıda gösterilen iki versiyonu kullanılacaktır:

$$
\begin{aligned}
& \Delta Y_{t}=\rho * Y_{t-1}+\sum_{i=1}^{k} \beta_{i} \Delta Y_{t-i}+\varepsilon_{t} \\
& \Delta Y_{t}=a+\rho * Y_{t-1}+\sum_{i=1}^{k} \beta_{i} \Delta Y_{t-i}+\varepsilon_{t}
\end{aligned}
$$

Yukarıdaki (1) numaralı denklem testin sabitsiz ve trendsiz, (2) numaralı denklem ise testin sabitli ve trendsiz versiyonlarını temsil etmektedir. ADF testinin sifir hipotezi serinin durağan olmadığ veya aynı anlama gelecek biçimde serinin birim kök içerdiği biçimindedir. Alternatif hipotez ise, serinin durağan olduğu veya aynı anlama gelecek biçimde serinin birim kök içermediği biçimindedir. Yukarıdaki denklemlerin tahmin edilmesiyle hesaplanan ADF test istatistikleri, diğerleri yanında MacKinnon (1996) kritik değerleri ile karşılaştırılarak değerlendirilmektedir. 


\subsection{Phillips-Perron (PP) Testi}

Phillips (1987) ve Phillips ve Perron (1988), hata terimleri arasındaki muhtemel otokorelasyonu gidermek için DF denklemlerine bağımlı değişken gecikmelerini ilave etmek yerine, parametrik olmayan bir yaklașımla test istatistiğinde bir düzeltme yapılmasını önermişlerdir. PP testinde, hata terimlerinin sadece birbiriyle ilişkili değil, aynı zamanda heterojen dağılabileceği de göz önüne alınmaktadır.

Test, hata terimleri varyansı ve uzun dönemli varyans için tutarlı tahminciler kullanarak DF test istatistiğinde bir düzeltme yapılması esası üzerine kuruludur. Düzeltmeye bağlı olarak hesaplanacak test istatistikleri DF dağılımına sahiptir ve bu nedenle testi sonuçlandırmak için DF tablo değerleri kullanılır.

\subsection{Kwiatkowski, Phillips, Schmidt ve Shin (1992) Testi}

Kwiatkowski, Phillips, Schmidt ve Shin (1992, bundan sonra KPSS), bir zaman serisinin deterministik trend, tesadüfi yürüyüş ve durağan hata terimlerinin toplamı olarak bileşenlerine ayrıştırılabileceğini varsaymıştır:

$$
\mathrm{y}_{\mathrm{t}}=\delta \mathrm{t}+\mathrm{r}_{\mathrm{t}}+\varepsilon_{\mathrm{t}}
$$

Yukarıdaki denklemde $t$ deterministik trendi, $\varepsilon_{\mathrm{t}}$ durağan, bağımsız ve aynı dağılıma sahip hata terimlerini, $r_{t}$ ise aşağıdaki şekilde tanımlanan bir tesadüfi yürüyüşs sürecini göstermektedir.

$$
r_{t}=r_{t-1}+u_{t}
$$

(4) numaralı denklemdeki $u_{t}$ sıfır ortalama ve $\sigma_{u}^{2}$ varyans ile bağımsız ve aynı dağılıma sahip bir rassal değişkendir. KPSS testinde sıfır hipotezi serinin trend durağan olduğunu ifade eder. Testin diğer bir versiyonunda (3) numaralı denklemde deterministik zaman trendi yoktur. Bu durumda sifir hipotezi serinin deterministik trend etrafında değil seviye değeri etrafında $\left(r_{0}\right)$ durağan olduğunu ifade eder. Test için asimptotik kritik değerler KPSS (1992)'de rapor edilmiştir. Hesaplanan test istatistiğinin, tablo değerinden büyük olması halinde sıfır hipotezi ret edilecektir.

\subsection{DF-GLS Testi}

Elliott, Rothenberg ve Stock (1996, bundan sonra ERS) ADF testinde kullanılan serileri trenden arındırarak ADF testinin gücünü optimize etmiştir. Test aşağıdaki regresyon denkleminin tahmini üzerine kuruludur:

$$
\Delta \mathrm{y}_{\mathrm{t}}^{\mathrm{d}}=\mathrm{a}_{0} \mathrm{y}_{\mathrm{t}-1}^{\mathrm{d}}+\sum_{\mathrm{i}=1}^{\mathrm{k}} \mathrm{a}_{\mathrm{i}} \Delta \mathrm{y}_{\mathrm{t}-\mathrm{i}}^{\mathrm{d}}+\varepsilon_{\mathrm{t}}
$$

(5) numaralı regresyon denkleminde $y_{t}^{d}$, y serisinin yerel (locally) olarak trenden arındırılmış halidir. Trendden arındırma işlemi "sadece sabitli" ve "hem sabitli hem trendli" olmak üzere iki ayrı durumda ele alınır. Birim kökü ifade eden sıfır hipotezi için, (5) numaralı denklemin tahminiyle $\mathrm{a}_{0}=0$ için hesaplanacak $\mathrm{t}$ istatistiğinin asimptotik dağılımı, sabitli denklem için DF dağılımına uyarken, sabitli ve trendli denklemde DF dağılımından farklıdır ve ERS (1996)' da rapor edilmiştir. 


\subsection{Point Optimal Testi}

ERS Point Optimal testi, DF-GLS testi gibi "sadece sabitli" ve "hem sabitli hem trendli” olmak üzere iki ayrı durum için hesaplanabilir. Test, durağanlığı incelenen serinin ve ayrıca testteki deterministik regresörlere bağlı olarak sabit ve trend değişkenlerinin öncelikli olarak dönüştürülmesi üzerine kuruludur. Dönüştürülmüş serilerin kullanıldığ 1 regresyon denklemlerinin hata terimleri kareleri toplamı ve varyans tahmini kullanılarak test istatistiği hesaplanır. ERS Point Optimal testi için kritik değerler "sadece sabitli" ve "hem sabitli hem trendli" durum için ayrı ayrı olmak üzere ERS(1996) Tablo 1'de rapor edilmiştir. Hesaplanan test istatistiğinin, ilgili tablo değerinden küçük olması halinde birim kökü ifade eden sıfır hipotezi ret edilecektir.

\subsection{Ng ve Perron (2001) Testleri}

$\mathrm{Ng}$ ve Peron (2001), GLS trendden arındırılmış seriler $\left(\mathrm{y}_{\mathrm{t}}^{\mathrm{d}}\right)$ üzerine kurulu dört ayrı test önermişlerdir. $\mathrm{Bu}$ testler $\mathrm{PP} \mathrm{Z}_{\alpha}$ ve $\mathrm{Z}_{t}$, Bhargava (1986) $\mathrm{R}_{1}$ ve ERS Point Optimal testlerde iyileştirmeler yapılarak elde edilmiş ve sırasıyla $\mathrm{MZ}_{\alpha}^{\mathrm{GLS}}, \mathrm{MZ}_{\mathrm{t}}^{\mathrm{GLS}}$, $\mathrm{MSB}^{\mathrm{GLS}}$ ve $\mathrm{MP}_{\mathrm{t}}^{\mathrm{GLS}}$ olarak isimlendirilmiştir. M testleri olarak da bilinen bu testler DF-GLS testi gibi "sadece sabitli" ve "hem sabitli hem trendli" olmak üzere iki ayrı durum için hesaplanabilir. Ayrıca testlerin sıfır ve alternatif hipotezleri ile karar kuralları, orijinal (iyileştirme yapılmamış) testlerle aynıdır.

\subsection{Lee ve Strazicich $(2003,2004)$ Testleri}

$\mathrm{Bu}$ çalışmada ayrıca yukarıda anlatılan testlerden farklı olarak yapısal kırılmayı dikkate alan birim kök testleri de kullanılmıştır. Bu amaçla içsel olarak bir ve iki kırılmaya izin veren sirasıyla Lee ve Strazicich (2004) ve Lee ve Strazicich (2003) testleri kullanılmıştır. Bu testlerde aşağıdaki veri üretim süreci ele alınmaktadır (Sivri ve Seven, 2017, s.54-55):

$$
\mathrm{y}_{\mathrm{t}}=\delta^{\prime} \mathrm{Z}_{\mathrm{t}}+\mathrm{e}_{\mathrm{t}}, \quad \mathrm{e}_{\mathrm{t}}=\beta \mathrm{e}_{\mathrm{t}-1}+\varepsilon_{\mathrm{t}}
$$

Burada $Z_{t}$ dişsal değişkenler vektörüdür ve $\varepsilon_{t} \sim$ iid $N\left(0, \sigma^{2}\right)$. Testin tek kırılmalı versiyonunda Model A sadece sabit terimde, Model $\mathrm{C}$ ise hem sabit terimde hem trend katsayısında bir defalık değişimi modellemektedir. Testin iki kırılmalı versiyonunda Model AA sadece sabit terimde, Model CC ise hem sabit terimde hem trend katsayısında iki defalık değişimi modellemektedir. Bu çalışmada Liu ve Tanner (1996) çalışması ile uyumlu olarak yapısal kırılmasız geleneksel testlerde olduğu gibi yapısal kırılmayı hesaba katan Lee ve Strazicich (2003, 2004) testlerinde de model, sabitli olarak kurulacaktır. Dolayısıyla ilgili testin yalnızca Model A versiyonu kullanılacaktır.

Lagrange Multiplier (Lagrange Çarpanı, bundan sonra LM) prensibi ile birim kök test istatistikleri aşağıdaki regresyon denklemi yardımı ile hesaplanmaktadır (Lee ve Strazicich, 2003 ve 2004): 


$$
\Delta y_{t}=\delta^{\prime} \Delta Z_{t}+\varnothing \bar{S}_{t-1}+u_{t}
$$

Birim kökü içeren sıfır hipotezini test etmek için hesaplanan LM test istatistiği, $\emptyset=$ 0 hipotezini test eden t-istatistiğidir. Söz konusu t-istatistiği, olası tüm kırılma tarihleri için hesaplanan istatistiklerin en küçüğü olarak seçilmektedir. Ayrıca seçilen t-istatistiğinin hesaplandığ Bir kırılmalı birim kök testi için kritik değerler Lee ve Strazicich (2004), iki kırılmalı birim kök testi için kritik değerler ise Lee ve Strazicich (2003)'de rapor edilmiştir.

Hem kırılmasız hem de kırılmalı birim-kök testlerinde Liu ve Tanner (1996)'in yöntemi izlenmek suretiyle sadece sabit terimde kırılmaya izin veren modeller kurularak analiz gerçekleştirilmiştir.

\section{Bulgular}

Durağanlık analizlerine geçmeden önce çalışmada oluşturulan serilerin şekilleri incelenecektir. 1992:I-2017:IV dönemine ait çeyreklik verilerle oluşturulan cari işlemler dengesinin GDP'ye oranı (\%) aşağıdaki Şekil 1'de gösterilmektedir.

Şekil 1: Türkiye Ekonomisi Cari İşlemler Dengesinin GDP’ye Oranı (\%)

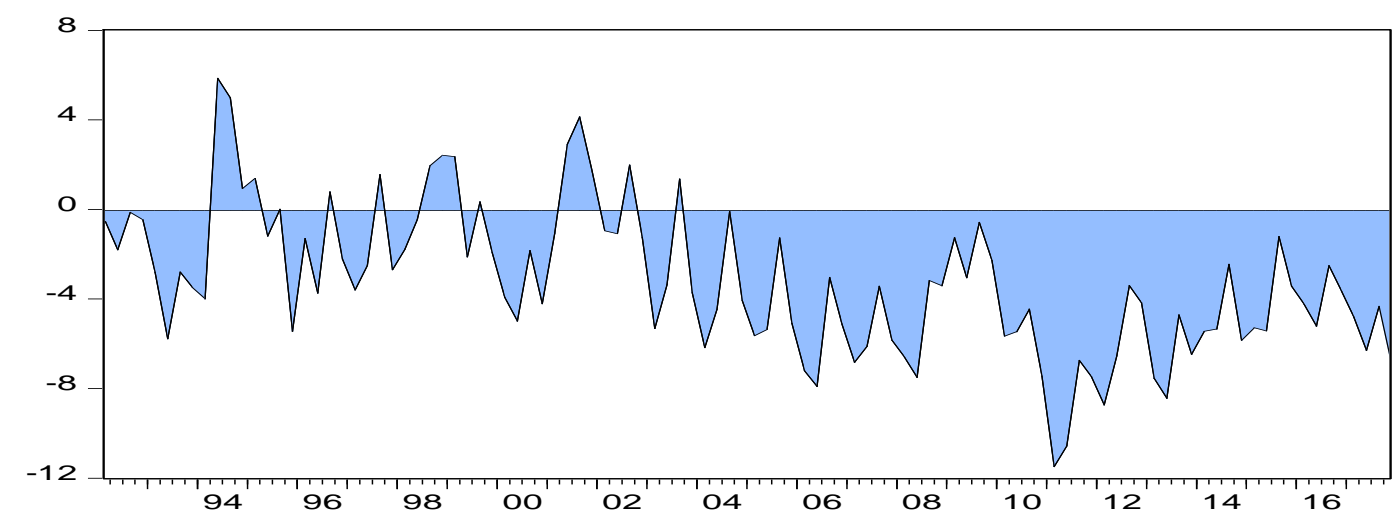

Türkiye ekonomisi cari işlemler dengesinin GDP'ye oranının incelenen dönem itibariyle çoğunlukla negatif bir değer aldığı, diğer bir ifadeyle cari dengenin açık verdiği ve bu açığın artış eğiliminde olduğu Şekil 1'de görülmektedir. İncelenen serinin ilgili dönemde ortalama değeri \% -3.20'dir. En yüksek cari açık oranı 2011 yılının ilk çeyreğinde \% 11.44 olarak gerçekleşmiştir. Ayrıca cari açık sorununun kronik hale gelmeye başladığı 2002 yılının ilk çeyreğinden 2017'nin son çeyreğine kadar olan dönemde ise ortalama cari açık oranı \% -4.7'dir. Türkiye ekonomisinde 2001 krizinin hemen sonrasında gerçekleştirilen reformlar, 2002 yılı itibariyle siyasi ve ekonomik istikrarın sağlanması ve güçlü ekonomiye geçiş programının başarı ile uygulanması gibi gelişmeler ülke ekonomisinde 2007 sonlarına kadar olumlu bir hava oluşturmuştur. Bu süreçte kronik hale gelen cari açık problemi ancak 2008 yılında ABD merkezli yaşanan krizin etkilerinin hissedilmesiyle beraber bir sorun olarak algılanmaya başlanmıştır. 1992:01-2017:12 dönemine ait 
aylık verilerle oluşturulan reel cari işlemler dengesi aşağıdaki Şekil 2'de gösterilmektedir.

Şekil 2: Türkiye Ekonomisi Reel Cari İşlemler Dengesi (Milyar \$)

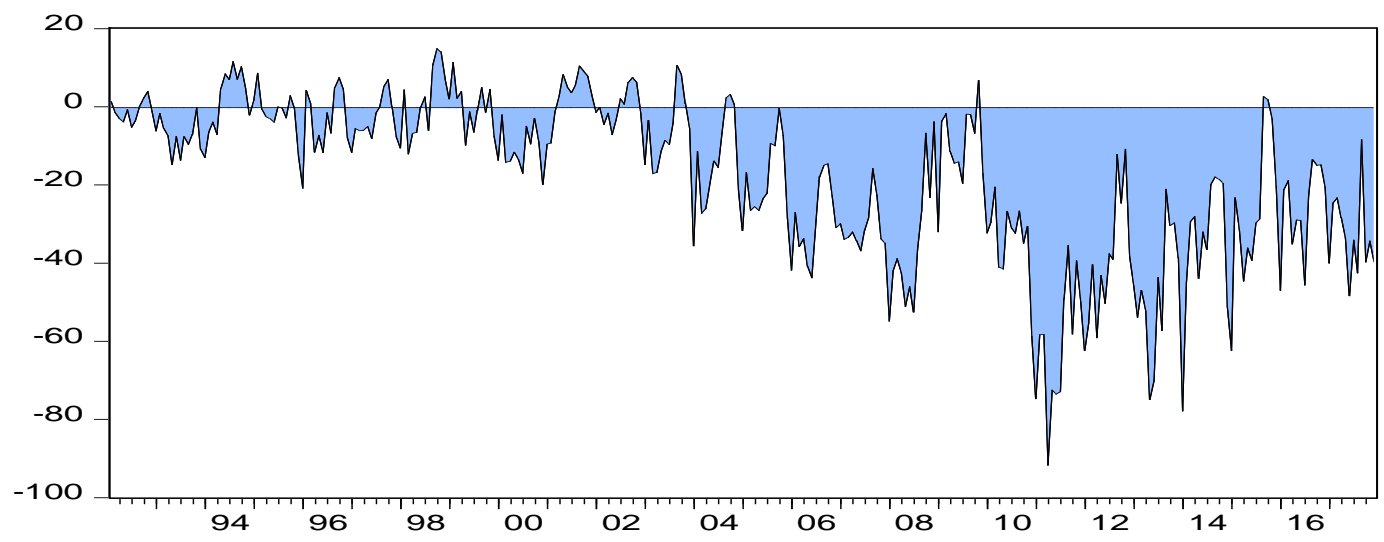

Şekil 2'de gösterilen Türkiye ekonomisi reel cari işlemler dengesinin, özellikle 2002 yılı sonrasındaki dönemde istisnai bazı dönemler hariç olmak kaydıyla negatif ve göreceli olarak büyük (mutlak değer olarak) değerler aldığı, diğer bir ifadeyle cari açık verdiği ve söz konusu açığın arttığı görülmektedir. Bu tespit genel olarak Şekil 1'de de gözlenmiştir. Seri 2009 krizi sonrası süreçte ithalatın büyük oranda azalması ile beraber çok kısa süreliğine artı değer almakta (cari fazla vermekte) ve hemen sonrasında negatif bölgede artış (mutlak değer olarak) göstermeye devam etmektedir. 2011 yılının üçüncü ayında 92 milyar dolar olarak gerçekleşen reel cari açık, incelenen dönemin en yüksek rakamı olarak kaydedilmektedir.

1992:01-2017:12 dönemine ait aylık verilerle oluşturulan kişi başına reel cari denge Şekil 3'de gösterilmektedir.

Şekil 3: Türkiye Ekonomisi Kişi Başına Reel Cari Denge (Milyar \$)

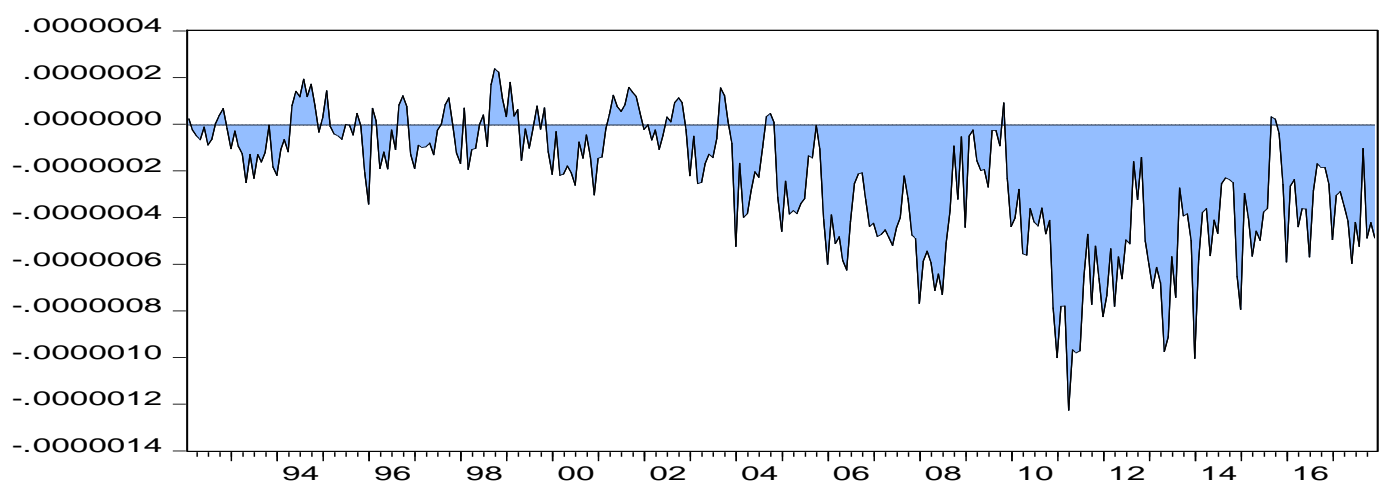

Şekil 3'de yer alan Türkiye ekonomisi kişi başına reel cari denge serisi, Şekil 1 ve Şekil 2 ile uyumlu olarak, özellikle 2002 yılından sonra cari açık sorununun ortaya çıktığını ve şiddetlendiğini göstermektedir. 2011 yılının üçüncü ayında rekor seviyeye ulaşan reel cari açık, kişi başına reel cari açık değerini de etkileyerek incelenen dönemde en yüksek seviyeye (1200\$) ulaşmasına sebep olmaktadır. 
Tablo 2: Kırılmasız Durağanlık Test Sonuçları

\begin{tabular}{|c|c|c|c|c|c|c|}
\hline SERILEF & \multicolumn{2}{|c|}{$\begin{array}{c}\text { (Cari İşlemler } \\
\text { Dengesi)/GDP } \\
(\%)\end{array}$} & \multicolumn{2}{|c|}{ Reel Cari Denge } & \multicolumn{2}{|c|}{$\begin{array}{l}\text { Kişi Başına Reel } \\
\text { Cari Denge }\end{array}$} \\
\hline & $\begin{array}{c}\text { Sabitsiz ve } \\
\text { Trendsiz }\end{array}$ & Sabitli & \begin{tabular}{|c|} 
Sabitsiz ve \\
Trendsiz
\end{tabular} & Sabitli & \begin{tabular}{|c|} 
Sabitsiz ve \\
Trendsiz
\end{tabular} & Sabitli \\
\hline $\mathrm{ADF}$ & $-0.53(7)$ & $-1.38(7)$ & $-1.08(13)$ & $-2.16(13)$ & $-1.23(13)$ & $-2.34(13)$ \\
\hline$\overline{\mathrm{PP}}$ & $-2.82^{* * *}(8)$ & $-4.92^{* * *}(8)$ & $-2.89^{* * * *}(13)$ & $-4.46^{* * * *}(4)$ & $-2.81^{* * *}(11)$ & $-4.72^{* * * *}(2)$ \\
\hline KPSS & - & $0.86^{* * * *}(8)$ & - & $1.58^{* * *}(14)$ & - & $1.50^{* * *}(14)$ \\
\hline DF-GLS & - & $-0.96(7)$ & - & $-1.22(13)$ & - & $-1.35(13)$ \\
\hline $\begin{array}{l}\text { Point } \\
\text { Optimal }\end{array}$ & - & $11.69(7)$ & - & $5.02(13)$ & - & $4.31^{*}(13)$ \\
\hline $\mathrm{MZ}_{\alpha}^{\mathrm{GLS}}$ & - & $-1.64(7)$ & - & $-4.52(13)$ & - & $-5.23(13)$ \\
\hline $\mathrm{MSB}^{\mathrm{GLS}}$ & - & $0.42(7)$ & - & $0.25^{*}(13)$ & - & $0.24^{*}(13)$ \\
\hline $\mathrm{MZ}_{\mathrm{t}}^{\mathrm{GLS}}$ & - & $-0.70(7)$ & - & $-1.13(13)$ & - & $-1.30(13)$ \\
\hline $\mathrm{MP}_{\mathrm{t}}^{\mathrm{GLS}}$ & - & $11.75(7)$ & - & $6.08(13)$ & - & $5.47(13)$ \\
\hline
\end{tabular}

Not: Parantez içinde verilen değerler ADF ve DF-GLS testleri için Schwarz bilgi kriterine göre hesaplanan gecikme uzunluğunu; PP ve KPSS testleri için Bartlett ağırlıklandırmalı Newey ve West (1994) yöntemi ile hesaplanan bant genişliğini; Point Optimal testi için Ng ve Perron (2001)'e göre modifiye edilmiş Schwarz bilgi kriterine göre hesaplanan gecikme uzunluğunu; M testleri için ERS tarafından önerilen ve Point Optimal testinden farklı olarak, trendden arındırılmış GLS verisi kullanılarak hesaplanan gecikme uzunluğunu göstermektedir. ***, ** ve * sırasıyla \%1, \%5 ve \%10 anlamlılık düzeyini göstermektedir.

Farklı şekillerde ölçülen cari denge serileri grafiksel olarak incelendikten sonra durağanlık testlerinin uygulanmasına geçilmiştir. $\mathrm{Bu}$ amaçla öncelikle yapısal kırılmayı dikkate almayan durağanlık testleri uygulanmış ve elde edilen sonuçlar Tablo 2'de gösterilmiştir. ${ }^{3}$

Tablo 2'de sunulan test istatistiklerine göre cari işlemler dengesinin GDP'ye oranının, durağanlık testlerinin sabitsiz ve trendsiz versiyonlarının kullanılmasına imkân veren $\mathrm{ADF}$ testinde durağan olmadığı, PP testinde ise durağan olduğu görülmektedir. Bunun yanında durağanlık testlerinin sadece sabitli versiyonlarının kullanılmasına imkân veren dokuz testin sekiz tanesinde serinin durağan olmadığ yalnızca bir tanesinde -PP testinde- serinin durağan olduğu yönünde sonuçlar elde edilmektedir. Sonuçlar bir bütün olarak değerlendirildiğinde, Türkiye ekonomisi cari işlemler dengesinin GDP'ye oranının ağırlıklı olarak durağan olmadığı görülmektedir.

Tablo 2 reel cari denge itibariyle incelendiğinde elde edilen sonuçların, cari işlemler dengesinin GDP'ye oranı kullanılarak elde edilen sonuçlar ile genel olarak aynı olduğu görülmektedir. Yukarıda incelenen ilk seride olduğu gibi durağanlık testlerinin sabitsiz ve trendsiz versiyonları kullanılarak elde edilen sonuçlar ADF

\footnotetext{
${ }^{3} \mathrm{Bu}$ çalışmadaki tüm ekonometrik analizler EViews9 ve GAUSS10 paket programları kullanılarak gerçekleştirilmiştir.
} 
testinde serinin durağan olmadığı, PP testinde ise serinin durağan olduğu yönündedir. Durağanlık testlerinin sadece sabitli versiyonlarının kullanılmasına imkân veren testlerde ise bir farklılık ortaya çıkmaktadır. Bu defa kullanılan dokuz testin yedi tanesinde serinin durağan olmadığ 1 , buna karşılık iki tanesinde -PP ve $\mathrm{MSB}^{\mathrm{GLS}}$ testlerinde- serinin durağan olduğu yönünde sonuçlar elde edilmektedir. Elde edilen sonuçlar bir bütün olarak değerlendirildiğinde Türkiye ekonomisi reel cari denge serisinin ağırlıklı olarak durağan olmadığı görülmektedir.

Tablo 2 kişi başına reel cari denge açısından incelendiğinde elde edilen sonuçların, reel cari denge kullanılarak elde edilen sonuçlar ile genel olarak aynı olduğu görülmektedir. Durağanlık testlerinin sabitsiz ve trendsiz versiyonları kullanılarak elde edilen sonuçlar yine ADF testinde serinin durağan olmadığı, PP testinde ise serinin durağan olduğu yönündedir. Durağanlık testlerinin sadece sabitli versiyonlarının kullanılmasına imkân veren testlerde ise bir farklılık ortaya çıkmaktadır. Bu defa gerçekleştirilen dokuz testin altı tanesinde serinin durağan olmadı̆̆ 1 , buna karşılık üç tanesinde -PP, Point Optimal ve MSB ${ }^{\mathrm{GLS}}$ testlerindeserinin durağan olduğu şeklinde sonuçlar elde edilmektedir. Sonuçlar bir arada değerlendirildiğinde Türkiye ekonomisi kişi başına reel cari denge serisinin ağırlıklı olarak durağan olmadığı görülmektedir.

Yapısal kırılmayı dikkate almayan birim kök testlerinin Türkiye ekonomisine ilişkin cari dengeyi temsil etmek üzere oluşturulan üç ayrı seriye uygulanması neticesinde ağırlıklı bir şekilde ilgili serilerin durağan olmadığı tespit edilmiştir. Bundan sonraki kısımda birim kök analizi yapısal kırılma hesaba katılarak yapılacaktır. Bu amaçla gerçekleştirilen ve bir yapısal kırılmayı dikkate alan Lee ve Strazicich (2004) test sonuçları aşağıdaki Tablo 3 'te görülmektedir.

Tablo 3: Tek Kırılmalı LM Test Sonuçları (Model A)

\begin{tabular}{l|c|c|c}
\hline & $\begin{array}{c}\text { (Cari İşlemler } \\
\text { Dengesi)/GDP }(\%)\end{array}$ & $\begin{array}{c}\text { Reel Cari } \\
\text { Denge }\end{array}$ & $\begin{array}{c}\text { Kişi Başına Reel } \\
\text { Cari Denge }\end{array}$ \\
\hline Gecikme Uzunluğu & 12 & 13 & 13 \\
\hline LM Test İstatistiği & -3.08 & $-4.07^{* *}$ & $-4.31^{* * *}$ \\
\hline Kırılma Tarihi & $2003:$ III & $2010: 12$ & $2010: 04$ \\
\hline B(t) & -1.77 & 4.72 & $0.0^{* *}$ \\
& $(-0.95)$ & $(0.50)$ & $(1.97)$ \\
\hline
\end{tabular}

Not: Gecikme uzunluğu, Ng ve Perron (1995) tarafından geliştirilen "genelden özele" yöntemiyle tespit edilmiştir. Parantez içindeki değerler $\mathrm{t}$ istatistiklerini göstermektedir. ***, ** ve * sırasıyla $\% 1, \% 5$ ve $\% 10$ anlamlılık düzeyini göstermektedir. Model A için tek kırılmalı LM Testi kritik değerleri $\% 1, \% 5$ ve $\% 10$ anlamlıllk düzeyleri için sırasıyla $-4.239,-3.566$ ve -3.211 olarak LeeStrazicich (2004)'ten elde edilmiştir. B(t) sabit terimdeki kırılmayı gösteren kukla değişkenidir. Kukla değiş̧kenlere ait kritik değerlerin elde edilmesinde normal dağılım tablosundan faydalanılmıştır ve bu değerler $\% 1, \% 5$ ve $\% 10$ anlamlılık düzeyleri için sırasıyla $2.576,1.96$ ve 1.645 'tir.

Bu çalışmada mevcut literatür izlenerek Lee ve Strazicich (2004) testinin sabit terimde bir kırılmaya izin veren ve Model A olarak isimlendirilen versiyonu kullanılmıştır. Tablo 3 cari işlemler dengesinin GDP'ye oranı açısından 
incelendiğinde LM test istatistiğinin -3.08 olarak bulunduğu görülmektedir. Test istatistiğinin, kritik değerlerden küçük olmamasına bağlı olarak sıfır hipotezi hiçbir anlamlılık düzeyinde reddedilememektedir. Buna göre bir yapısal kırılmanın dikkate alınması durumunda dahi Türkiye ekonomisi cari işlemler dengesinin GDP'ye oranı durağan değildir.

Reel cari denge açısından Tablo 3 incelendiğinde, LM test istatistiğinin -4.07 olarak bulunduğu görülmektedir. Bu değer \% 5 anlamlılık düzeyinde kritik değerden küçüktür. Dolayısıyla sabit terimdeki bir kırılmanın dikkate alınması durumunda Türkiye ekonomisi reel cari denge serisi \% 5 anlamlılık düzeyinde durağandır. Modele göre yapısal kırılma tarihi 2010:12 olarak tespit edilmiştir.

Tablo 3 kişi başına reel cari denge açısından incelendiğinde LM test istatistiğinin 4.31 olarak bulunduğu görülmektedir. Bu değer \% 1 anlamlılık düzeyinde kritik değerden küçüktür. Buna bağlı olarak sabit terimdeki bir kırılmanın dikkate alınması durumunda Türkiye ekonomisi kişi başına reel cari denge serisi \% 1 anlamlılık düzeyinde durağandır. Modele göre yapısal kırılma tarihi 2010:04 olarak bulunmuştur ve bu tarih reel cari denge serisi için bulunan tarihe oldukça yakındır.

Türkiye ekonomisine ilişkin cari açık serilerinde iki kırılma olabileceğini dikkate alarak gerçekleştirilen Lee ve Strazicich (2003) test sonuçları aşağıdaki Tablo 4'de sunulmaktadir.

Tablo 4: İki Kırılmalı LM Test Sonuçları (Model AA)

\begin{tabular}{l|c|c|c}
\hline & $\begin{array}{c}\text { (Cari İşlemler } \\
\text { Dengesi)/GDP }(\%)\end{array}$ & $\begin{array}{c}\text { Reel Cari } \\
\text { Denge }\end{array}$ & $\begin{array}{c}\text { Kişi Başına Reel } \\
\text { Cari Denge }\end{array}$ \\
\hline Gecikme Uzunluğu & 12 & 13 & 13 \\
\hline LM Test İstatistiği & $-4.16^{* *}$ & $-4.74^{* * *}$ & $-4.92^{* * *}$ \\
\hline Kırılma Tarihi-1 & $1997:$ II & $2008: 09$ & $1999: 12$ \\
\hline Kır1ma Tarihi-2 & $2012: \mathrm{I}$ & $2010: 04$ & $2013: 05$ \\
\hline B1(t) & $5.18^{* * *}$ & 0.52 & $0.0^{* *}$ \\
& $(2.74)$ & $(0.05)$ & $(0.63)$ \\
\hline B2(t) & $3.08^{*}$ & $20.79^{* *}$ & $0.0^{* *}$ \\
& $(1.77)$ & $(2.22)$ & $(2.47)$ \\
\hline
\end{tabular}

Not: Gecikme uzunluğu, Ng ve Perron (1995) tarafindan geliştirilen "genelden özele" yöntemiyle tespit edilmiştir. Parantez içindeki değerler $t$ istatistiklerini göstermektedir. ***, ** ve * sırasıyla $\% 1, \% 5$ ve $\% 10$ anlamlılık düzeyini göstermektedir. Model AA için iki kırılmalı LM Testi kritik değerleri $\% 1, \% 5$ ve $\% 10$ anlamlılık düzeyleri için sırasıyla $-4.545,-3.842$ ve -3.504 olarak LeeStrazicich (2003)'ten elde edilmiştir. B1(t) ve B2(t) sabit terimdeki kırılmayı gösteren kukla değişkenlerdir. Kukla değişkenlere ait kritik değerlerin elde edilmesinde normal dağılım tablosundan faydalanılmıştır ve bu değerler $\% 1, \% 5$ ve $\% 10$ anlamlılık düzeyleri için sırasıyla 2.576 , 1.96 ve 1.645 'tir.

Bu çalışmada mevcut literatür izlenerek Lee ve Strazicich (2003) testinin sabit terimde iki kırılmaya izin veren ve Model AA olarak isimlendirilen versiyonu kullanılmıştır. Tablo 4 cari işlemler dengesinin GDP'ye oranı açısından incelendiğinde LM test istatistiğinin -4.16 olduğu görülmektedir. Bu değer \% 5 anlamlılık düzeyinde kritik değerden küçüktür ve buna bağlı olarak sıfır hipotezi 
reddedilir. Buna göre iki yapısal kırılmanın dikkate alınması durumunda Türkiye ekonomisi cari işlemler dengesinin GDP'ye oranı \% 5 anlamlılık düzeyinde durağandır ve cari dengenin (açıkların) sürdürülebilir olduğunu ima etmektedir. Sabit terimdeki ilk kırılmayı ifade eden katsayı \%1 düzeyinde, ikinci kırılmayı ifade eden katsayı ise \% 10 düzeyinde istatistiksel olarak anlamlıdır. Ayrıca kırılma tarihleri olarak 1997:II ve 2012:I bulunmuştur.

Tablo 4'e göre reel cari denge serisi için LM test istatistiği -4.74 olarak bulunmuştur. Buna göre sıfır hipotezi \% 1 anlamlılık düzeyinde reddedilmektedir. Bu bulgu, iki yapısal kırılmanın dikkate alınması durumunda Türkiye ekonomisi reel cari denge (açık) serisinin sürdürülebilir olduğunu ima etmektedir. Sabit terimdeki ilk kırılmayı ifade eden katsayı anlamlı çıkmamakla beraber, ikinci kırılmayı ifade eden katsayı \% 5 düzeyinde istatistiki olarak anlamlıdır. Kırılma tarihleri olarak 2008:09 ve 2010:04 dönemleri tespit edilmiştir.

Tablo 4'de sunulan istatistiklere göre kişi başına reel cari denge serisi için LM test istatistiği -4.92 olarak bulunmuştur. $\mathrm{Bu}$ değer \% 1 düzeyinde tablo değerinden küçüktür ve buna bağlı olarak sıfır hipotezi ret edilir. Bu bulgu, iki yapısal kırılmanın dikkate alınması durumunda Türkiye ekonomisi kişi başına reel cari denge (açık) serisinin durağan ve sürdürülebilir olduğunu göstermektedir. Sabit terimdeki kırılmaları ifade eden iki katsayı da istatistiksel olarak \% 5 düzeyinde anlamlıdır. Ayrıca test sonuçlarına göre kırılma tarihleri olarak 1999: 12 ve 2013:M5 dönemleri bulunmuştur.

Kırılmalı LM test sonuçları bir bütün olarak değerlendirildiğinde, cari işlemler dengesinin GDP'ye oranının tek kırılmaya izin veren modelde durağan olmadığı, iki kırılmaya izin veren modelde ise durağan olduğu bulunmuştur. Bunun yanında reel cari açık ve kişi başına reel cari açık serileri ise hem tek kırılmalı hem de iki kırılmalı test sonuçlarına göre durağan bulunmuştur.

\section{Sonuç ve Değerlendirme}

Bu çalışmada 1992:01-2017:12 dönemi Türkiye ekonomisine ilişkin cari açıkların değerlendirilmesi, genel kabul gören sürdürülebilirlik oranlarına göre hangi noktada bulunduğunun tespit edilmesi ve bu karara varırken de ekonometrik analizlerden elde edilen sonuçlar ile yorumlar ve politika önerilerinde bulunulması amaçlanmaktadır.

$\mathrm{Bu}$ çalışmada öncelikle cari açık serilerinin oluşturulması üzerinde durulmuştur. $\mathrm{Bu}$ amaçla cari açığın sürdürülebilirliğinin tespiti için analiz edilmek üzere üç farklı seri oluşturulmuştur: Bu serilerden ilki 1992:I-2017:IV dönemini kapsayan çeyreklik “(Cari İşlemler Dengesi)/GDP” serisi, ikincisi 1992:01-2017:12 dönemini kapsayan aylık "Reel Cari İşlemler Dengesi” ve üçüncüsü de aynı dönemi kapsayan yine aylık "Kişi Başına Reel Cari Denge" serisidir.

Çalışmanın ikinci aşamasında oluşturulan cari açık serilerinin durağanlığının incelenmesine geçilmiştir. Analizden elde edilen sonuçlar genel olarak değerlendirildiğinde klasik birim-kök testlerine göre başta cari işlemler dengesinin 
GDP'ye oranı olmak üzere bu çalışmada incelenen tüm serilerin durağan olmadığı görülmüştür. Dolayısıyla geleneksel testler, Türkiye'de cari açıkların sürdürülebilir olmadığını göstermektedir.

Esasında durağan olan serilerin durağan bulunmaması durumuyla karşılaşma riskini ortadan kaldırmak maksadıyla uygulanan tek kırılmalı ve iki kırılmalı LM birimkök testi sonuçları ise şunları göstermektedir: Tek kırılmalı LM testinde cari işlemler dengesinin GDP'ye oranı durağan değildir. İki kırılmaya izin veren LM testinde ise ilgili seri \%5 anlamlılık düzeyinde durağan bulunmuştur. Reel cari açık ve kişi başına reel cari açık serileri ise hem tek kırılmalı hem de iki kırılmalı LM test sonuçlarına göre durağan bulunmuştur.

Amerikan Merkez Bankası FED'in 2013 yılının ortaları itibariyle faiz artırımına gitme kararı ile beraber dünya genelinde yaşanan finansal çalkantılar, özellikle cari açık problemi ile karşı karşıya olan Türkiye, Hindistan, Endonezya, Brezilya ve Güney Afrika gibi ülkelerin "kırılgan beşli" olarak anılmasına sebep olmuştur. Kırılgan bir ekonomik yapı içerisinde bulunan Türkiye'nin yabancı sermaye hareketlerinden, FED'in faiz kararlarından ve dolayısıyla dış gelişmelerden etkilenmeye müsait yapısı, artan oranlı olarak artan cari açıkları ile bir araya geldiği zaman durum daha kritik olarak göze çarpmaktadır. Çalışmanın sonucu itibariyle cari açıkların sürdürülebilir olduğu yönündeki tespit, sorunların görmezden gelinmesinin bir mahsuru olmadığı ya da sürdürülebilir olduğu için cari açıkların ekonomi için herhangi bir sorun teşkil etmeyeceği şeklinde yorumlanmamalıdır. Bu çalışmada kullanılan yöntem, durağanlık test sonuçlarına göre sürdürülebilir ya da sürdürülemez şeklinde iki net yorumu gerektirmektedir. Her ne kadar sürdürülebilirlik yönünde sonuç elde edilmiş olsa da durağanlığın yüksek bir (Cari İşlemler Dengesi)/GDP ortalamasında elde edilmiş olması ve Türkiye ekonomisinin içinde bulunduğu olumsuz şartlar, tedbirli bir sürdürülebilirlik kavramını ön plana çıkarmaktadır. Bu durumun gerekçesi, hafif bir etki ile de olsa durağanlığın elde edildiği anlamlılık seviyesinin $\% 1$ değil, $\% 5$ olması ve kuvvetli bir etki ile de durağanlığın yüksek ortalamalar etrafında elde ediliyor olmasıdır. Kırılgan yapısı ile dış etkilerden çabuk ve önemli ölçüde etkilenen ülke ekonomisi, literatürde kriz eşiği olarak ifade edilen seviyelerde ( \%4 - \%5) gerçekleşen (Cari İşlemler Dengesi)/GDP oranı ile gerçekçi analizlere tabi tutulmalı ve çözüm odaklı politikalar üretilmelidir.

\section{Kaynakça}

Bhargava, A. (1986). On the theory of testing for unit roots in observed time series. Review of Economic Studies, 53(3), 369-384.

Campbell, J. Y. ve Shiller, R. J. (1987). Cointegration and tests of present value models. Journal of Political Economy, 95(5), 1062-1088.

Cashin, P. ve McDermott, C. J. (1998). Are Australia's current account deficits excessive? Economic Record, 74(227), 346-361. 
Chen, S. W. (2011). Current account deficits and sustainability: Evidence from the OECD countries. Economic Modelling, 28(4), 1455-1464.

Dickey, D. A. ve Fuller, W. A. (1979). Distribution of the estimators for autoregressive time series with a unit root. Journal of the American Statistical Association, 74(366), 427-431.

Elliott, G., Rothenberg, T. J. ve Stock, J. H. (1996). Efficient tests for an autoregressive unit root. Econometrica, 64(4), 813-836.

Fountas, S. ve Wu, J. L. (1999). Are the U.S. current account deficits really sustainable? International Economic Journal, 13(3), 51-58.

Ghosh, A. R. (1995). International capital mobility amongst the major industrialized countries: Too little or too much? The Economic Journal, 105(428), 107-128.

Ghosh, A. R. ve Ostry, J. D. (1995). The current account in developing countries: A perspective from the consumption-smoothing approach. The World Bank Economic Review, 9(2), 305-333.

Hakkio, C. S. ve Rush, M. (1991). Is the budget deficit "too large?" Economic Inquiry, 29(3), 429-445.

Husted, S. (1992). The emerging US current account deficit in the 1980s: A cointegration analysis. The Review of Economics and Statistics, 74(1), 159-166.

Kwiatkowski, D., Phillips, P. C., Schmidt, P. ve Shin, Y. (1992). Testing the null hypothesis of stationarity against the alternative of a unit root: How sure are we that economic time series have a unit root? Journal of Econometrics, 54(1-3), 159-178.

Lee, J. ve Strazicich, M.C. (2003). Minimum Lagrange multiplier unit root test with two structural breaks. Review of Economics and Statistics, 85(4), 1082-1089.

Lee, J. ve Strazicich, M. C. (2004). Minimum LM unit root test with one structural break. Manuscript, Department of Economics, Appalachian State University, 116.

Liu, P. C. ve Tanner, E. (1996). International intertemporal solvency in industrialized countries: Evidence and implications. Southern Economic Journal, 62(3), 739-749.

MacKinnon, J.G. (1996). Numerical distribution functions for unit root and cointegration tests. Journal of Applied Econometrics, 11(6), 601-618.

Matsubayashi, Y. (2005). Are US current account deficits unsustainable? Testing for the private and government intertemporal budget constraints. Japan and the World Economy, 17(2), 223-237. 
Milesi-Ferretti, G. M. ve Razin, A. (1996). Sustainability of persistent current account deficits. National Bureau of Economic Research (NBER) Working Paper No. 5467, 1-31.

Newey, W. K. ve West, K. D. (1994). Automatic lag length selection in covariance matrix estimation. Review of Economic Studies, 61(4), 631-653.

$\mathrm{Ng}, \mathrm{S}$. ve Perron, P. (1995). Unit root tests in ARMA models with data-dependent methods for the selection of the truncation lag. Journal of the American Statistical Association, 90(429), 268-281.

$\mathrm{Ng}$, S. ve Perron, P. (2001). Lag length selection and the construction of unit root tests with good size and power. Econometrica, 69(6), 1519-1554.

Phillips, P. C. B. (1987). Time series regression with a unit root. Econometrica, 55(2), 277-301.

Phillips, P. C. B. ve Perron, P. (1988). Testing for a unit root in time series regression. Biometrika, 75(2), 335-346.

Sivri, U. ve Seven, B. (2017). Ortalama tüketim eğilimi durağan mıdır? Türkiye ekonomisi için bir zaman serisi analizi. Anadolu İktisat ve İsletme Dergisi, 1(1), 50-65.

Trehan, B. ve Walsh, C. (1991). Testing intertemporal budget constraints: Theory and applications to U.S. federal budget and current account deficits. Journal of Money, Credit and Banking, 23(2), 206-223.

TÜİK (2018a). Konularına göre istatistikler, Nüfus ve demografi, Genel nüfus sayımları. http://www.tuik.gov.tr/PreTablo.do?alt_id=1059 (Erişim: 24.02.2018).

TÜİK (2018b). Konularına göre istatistikler, Nüfus ve demografi, Adrese dayalı nüfus kayit sistemi. http://www.tuik.gov.tr/PreTablo.do?alt_id=1059 (Erişim: 24.02.2018).

Wickens, M. R. ve Uctum, M. (1993). The sustainability of current account deficits: A test of the US intertemporal budget constraint. Journal of Economic Dynamics and Control, 17(3), 423-441.

$\mathrm{Wu}$, J. L. (2000). Mean reversion of the current account: Evidence from the panel data unit-root test. Economics Letters, 66(2), 215-222.

$\mathrm{Wu}$, J. L., Chen, S. L. ve Lee, H. Y. (2001). Are current account deficits sustainable? Evidence from panel cointegration. Economics Letters, 72(2), 219224. 